\title{
Knowledge, attitude and practice about the risk factors of ischemic stroke and warning symptoms- A case control study
}

\author{
Sumit Kumar Singh ${ }^{1, *}$, Dipak Kumar Dhar ${ }^{2}$ \\ ${ }^{1}$ PG Student, ${ }^{2}$ Tutor, ${ }^{1}$ Dept. of Community Medicine, ${ }^{2}$ Dept. of Physiology, Himalayan Institute of Medical Sciences, Swami Ram Nagar, \\ Jolly Grant, Dehradun, Uttarakhand \\ *Corresponding Author: Sumit Kumar Singh \\ Email: ssumitkumar94@gmail.com
}

\begin{abstract}
Introduction: Stroke is a neurological defect that could result in death thus the importance of evaluating the existing knowledge, attitude, and practice (KAP) is essential for stroke control.

Objective: Our study objective was to assess the knowledge, attitude and perception of risk factors and warning symptoms of ischemic stroke among controls and caregivers attending in a tertiary care hospital.

Materials and Methods: A matched (age and sex) case control study was planned to assess the knowledge, attitude and perception of risk factors and warning symptoms of Ischemic stroke among controls and caregivers in a tertiary care centre for a period of one year. The Sample size was calculated for matched case control (1:1 ratio) by n-master software and came out to be 189 pairs. Consecutive sampling method was used to select caregivers and controls. The controls were selected from the same hospital. The association between various risk factor and warning symptoms of ischemic stroke has been investigated. Z-test was implemented to estimate risk factor and warning symptom of Ischemic stroke among caregivers and controls.

Results: Our result revealed that most of subjects were aged 40-59 years, males (69.8\%), and (77.2\%) was literate. The KAP questionnaire was administered to 189 participants each from both groups. Majority (69.84\%) among caregiver while only $48.67 \%$ in control group knew about the risk factors of stroke. Majority (65.6\%) among the caregiver while only $30 \%$ in control knew about the warning signs of stroke. Majority of the respondents believed that ischemic stroke is preventable and stroke can occur more than one time and affects daily activity. Conclusions: The level of KAP toward stroke risk factors and warning symptoms was inadequate among the majority of control participants. Though it was observed that good KAP was associated with high education and young age.
\end{abstract}

Keywords: Ischemic stroke, Risk factors, Warning symptoms.

\section{Introduction}

All over the world about twenty million people suffer from stroke, among these fifteen million will survive while five million will die as a sequel and of those who ride out, five million will be disabled every year. ${ }^{1}$

Without public knowledge and the right attitude and practices, stroke burden cannot be reduced. For instance, it is important to know that therapeutic opportunities in stroke are limited. Delay in hospitalization contributes to high mortality and morbidity in stroke but ignorance about stroke symptoms, poor infrastructure, and hesitancy about hospital admission even when infrastructure and access are available often leads to delay. ${ }^{2}$ Further, there is a lack of knowledge and indifference about that timely treatment of hypertension and appropriate lifestyle changes that may help to decrease the incidence of stroke and morbidity among stroke-survivors in the long run. ${ }^{3}$

Adequate general knowledge about stroke could result in a quick and correct identification of stroke thus good management within the estimated time. ${ }^{4}$

This study was assessed to evaluate the knowledge, attitudes, and practices (KAP) of adult subjects regarding risk factors, warning symptoms for stroke that intended to develop strategies for controlling the stroke risk factors.

\section{Materials and Methods}

This case control study was conducted in a tertiary care hospital in Dehradun, Uttarakhand, India. Data collected for a 1-year period i.e., 1 July 2017 to 30 June 2018 and was analyzed Ethical approval was obtained from the University and a written consent was taken from all study subjects before including them in the study. It was assumed that $50 \%$ is the proportion of exposed controls and $5 \%$ is the level of significance with power $90 \%$ in order so as to detect a threefold increased risk ${ }^{5}$ and using the formula- $n=Z^{2} 1-\alpha / 2$ $[(1-\mathrm{P} 1) / \mathrm{P} 1+(1-\mathrm{P} 2) / \mathrm{P} 2] /[\operatorname{loge}(1-\varepsilon)]^{2}$

The Sample size was calculated for matched case control (1:1 ratio) by $\mathrm{n}$-master software. A minimum number of required pairs of caregiver and control came out to be 189 . Predesigned and pretested modified questionnaire for WHO STEP-wise approach to chronic disease risk factor surveillance $^{6}$ and WHO STEP wise approach to stroke surveillance were used for data collection. One control was selected for each caregiver. Questionnaire includes 4 sections and from each section following information has been collected-

Section I: Household information and individual information like Age, Sex, Education, marital status, etc.

Section II: Includes Knowledge about risk factors of stroke. Like - Alcohol and tobacco use, diet, Physical activity etc.

Section III: Includes Knowledge about warning signs of stroke. Like, weakness of one side of the body, Paralysis of one side of the body, Dizziness, Shortness of breath etc. Section IV: Includes response to an event of stroke. Like- call a general practitioner or family doctor, ask, family members or relatives to help, go to the hospital etc.

The data from the included questionnaires were analyzed using Statistical Package for Social Science (SPSS) program 
(V. 22) then tabulated. Test used was $\mathrm{Z}$ test. $\mathrm{P}$ values $<0.05$ were considered statistically significant.

\section{Results}

Table 1: General profile of caregiver

\begin{tabular}{|l|c|}
\hline Demographic profile & Caregiver $(\mathbf{n = 1 8 9})$ \\
\hline Gender & $132(69.8)$ \\
\hline Male & $57(30.2)$ \\
\hline Female & $59(31.2)$ \\
\hline Age group & $83(43.9)$ \\
\hline $20-39$ & $45(23.8)$ \\
\hline $40-59$ & $2(1.1)$ \\
\hline $60-80$ & \\
\hline$>80$ & $43(22.8)$ \\
\hline Education & $146(77.2)$ \\
\hline Illiterate
\end{tabular}

Table 1, depicts general profile of the caregiver. All subjects were distributed in a range of 20 years age groups. Among Caregiver maximum respondents were in age group of 40-60 years $(44 \%)$. Least participants were found in $>80$ years age group. According to their educations wise distribution of caregivers shows that majority of subjects were literate i.e. (77.2\%) and only (22.8\%) were illiterate.

Table 2: Knowledge about risk factors of ischemic stroke

\begin{tabular}{|l|c|c|c|}
\hline \multicolumn{1}{|c|}{ Risk factors of stroke } & $\begin{array}{c}\text { Caregiver } \\
\text { n=189 }\end{array}$ & $\begin{array}{c}\text { Control } \\
\text { n=189 }\end{array}$ & p-value \\
\hline Knowledge about risk factor of stroke & \multicolumn{1}{|c|}{} \\
\hline No & $57(30.16)$ & $97(51.33)$ & $0.00 *$ \\
\hline Yes & $132(69.84)$ & $92(48.67)$ & $0.00 *$ \\
\hline Stress & $82(62.12)$ & $48(52.17)$ & 0.14 \\
\hline Hypertension & $80(60.60)$ & $40(43.47)$ & $0.01 *$ \\
\hline Alcohol & $60(45.45)$ & $47(51.08)$ & 0.41 \\
\hline Smoking & $56(42.42)$ & $53(57.60)$ & $0.02 *$ \\
\hline Old age & $35(26.51)$ & $22(23.91)$ & 0.66 \\
\hline Exercise & $32(24.24)$ & $26(28.26)$ & 0.50 \\
\hline Diet & $29(21.96)$ & $36(39.13)$ & $0.005 *$ \\
\hline Diabetes & $26(19.69)$ & $21(22.82)$ & 0.57 \\
\hline Obesity & $24(18.18)$ & $18(19.56)$ & 0.79 \\
\hline Cholesterol & $17(12.86)$ & $12(13.04)$ & 0.97 \\
\hline Others & $41(31.06)$ & $27(29.34)$ & 0.78 \\
\hline
\end{tabular}

Statistically significant (p value $*<0.05, * *<0.001, * * *<0.0001)$

Out of the 378 participants, only 224(59.2\%) were knew about the risk factors for Ischemic stroke. Majority $(69.84 \%)$ among caregiver while only $48.67 \%$ in control group knew about the risk factors of stroke. According to caregivers most common risk factors of stroke were stress and hypertension (62.2\% and $60.60 \%$ respectively) while in controls smoking and stress (57\% and 52\% respectively) were most common risk factors. A statistically significant difference to know hypertension / diet / \& smoking are risk factor for stroke was found among both caregivers and control. Among other known risk factors were heart disease, atherosclerosis, poor hygiene, cancer, hereditary, migraine and oral contraceptive pills.

Table 3: Knowledge about warning signs of ischemic stroke

\begin{tabular}{|l|c|c|c|}
\hline \multicolumn{1}{|c|}{ Warning sign of stroke } & Caregiver $\mathbf{n = 1 8 9}$ & Control (n=189) & p-value \\
\hline Knowledge about warning sign of stroke & & $128(67.72)$ & $0.00 *$ \\
\hline No & $59(31.21)$ & $58(30.68)$ & $0.00 *$ \\
\hline Yes & $124(65.60)$ & $27(46.55)$ & 0.90 \\
\hline Headache & $59(47.58)$ & $25(43.10)$ & 0.57 \\
\hline Weakness: one side of body & $59(47.58)$ & $17(29.31)$ & $0.03 *$ \\
\hline Paralysis: one side of body & $58(46.77)$ & $22(37.93)$ & 0.75 \\
\hline Dizziness & $44(35.48)$ & $13(22.41)$ & 0.14 \\
\hline Difficulty speaking & $41(33.06)$ & $27(46.55)$ & $0.02 *$ \\
\hline Tiredness & $35(28.22)$ & & \\
\hline
\end{tabular}




\begin{tabular}{|l|c|c|c|}
\hline Numbness/tingling & $23(18.54)$ & $8(13.79)$ & 0.43 \\
\hline Shortness of breath & $22(17.74)$ & $19(32.75)$ & $0.02 *$ \\
\hline Blurred vision & $22(17.74)$ & $15(25.86)$ & 0.21 \\
\hline Nausea /vomiting & $20(16.12)$ & $16(27.58)$ & 0.07 \\
\hline Paralysis: any part of body & $17(13.7)$ & $4(6.89)$ & 0.18 \\
\hline Weakness: any part of body & $16(12.9)$ & $6(10.34)$ & 0.62 \\
\hline Others & $35(28.22)$ & $14(24.13)$ & 0.56 \\
\hline
\end{tabular}

Statistically significant (p value $*<0.05, * *<0.001, * * *<0.0001$ )

Majority (65.6\%) among the caregivers while only 30\% in control knew about the warning signs of stroke. According to caregivers most commonly recognized warning sign of stroke was weakness of one side of body $(47.58 \%)$ while among controls headache and tiredness ( $46.55 \%$ for both) were most common warning signs. In caregivers $10-48 \%$ and in controls $7-43 \%$ recognized dizziness/weakness and paralysis of one side of the body/weakness and paralysis of any part of the body and numbness and tingling of any part or one side of the body as one of the warning signs for stroke. Regarding warning sign of stroke significant difference was found only for tiredness, Shortness of breath and paralysis of one side of body both among caregivers and controls. Others warning signs identified by respondents were numbness one side, fever, sweating, chest pain, fainting and collapse.

Table 4: Perception of respondents towards ischemic stroke among caregivers and controls

\begin{tabular}{|c|c|c|c|}
\hline Perception & $\begin{array}{c}\text { Caregiver } \\
\mathrm{N}=189\end{array}$ & $\begin{array}{c}\text { Control } \\
\mathrm{N}=189\end{array}$ & $\begin{array}{l}\text { Z-test, } \\
\text { p-value }\end{array}$ \\
\hline \multicolumn{4}{|c|}{ Stroke is preventable } \\
\hline Yes & $139(73.54)$ & $111(58.73)$ & \multirow[t]{2}{*}{$9.26(0.002) * *$} \\
\hline No & $50(26.46)$ & $78(41.27)$ & \\
\hline \multicolumn{4}{|c|}{ Persons have stroke more than once } \\
\hline Yes & $143(75.66)$ & $130(68.78)$ & \multirow[t]{2}{*}{$2.23(0.14)$} \\
\hline No & $46(24.34)$ & $59(31.22)$ & \\
\hline \multicolumn{4}{|c|}{ Stroke has effect on daily activity } \\
\hline Yes & $157(83.07)$ & $150(79.37)$ & \multirow[t]{2}{*}{$0.85(0.36)$} \\
\hline No & $32(16.93)$ & $39(20.63)$ & \\
\hline
\end{tabular}

Statistically significant (p value $*<0.05, * *<0.001, * * *<0.0001)$

Majority of the respondents believed that, ischemic stroke is preventable and it was found statistically significant, for both caregiver and control group. Majority of subjects in both caregivers and controls believed that stroke can occur several times and affects daily activity but it was not found to be significant.

\section{Discussion}

In the present study there were $132(69.8 \%)$ men and 57 $(30.2 \%)$ women. All subjects were distributed in a range of 20 years age groups. Among Caregiver maximum respondents were in age group of 40-60 years $(44 \%)$. Least participants were found in $>80$ years age group. According to their education wise distribution of caregivers shows that majority of subjects were literate i.e. (77.2\%) and only $(22.8 \%)$ were illiterate.

Among respondents, almost similar result was seen in age group of 40-60 years (37\%) and least participants were found in $>80$ years age group. ${ }^{7}$ According to their Educations wise distribution Similar result was reported by Aldebasi KA in which that majority of subjects were literate i.e. (80\%) and only $(20 \%)$ were illiterate. ${ }^{8}$

In our study, most common risk factors of stroke were emerged as stress and hypertension $(62.2 \%$ and $60.60 \%$ respectively) while in control groups, smoking and stress (57\% and 52\% respectively) were most common risk factors.
Pandian JD et al. found that hypertension in $79(54 \%)$ and diabetes in $45(31 \%)$ subjects were the two most common identified risk factors. ${ }^{7}$ Similar result was reported by Bhat $\mathrm{AB}$ et al. in which it was found that the most common identified stroke risk factor was stress $(\mathrm{n}=75,80.6 \%) .{ }^{9}$

It was found in our study that-most commonly, recognized warning sign of stroke was weakness of one side of body $(47.58 \%)$ while among controls headache and tiredness $(46.55 \%$ for both) were most common warning signs. Similar, result was found in study done by Aldebasi KA which reported that most commonly recognized warning sign of stroke was weakness of arm, leg and face i.e., (59.2\%) followed by dizziness/trouble walking (49.6\%). ${ }^{8}$ Majority of the respondents believed positively that Ischemic Stroke is preventable disease i.e., $73.5 \%$ in caregiver and $58.7 \%$ in control. it was statistically significant for both caregiver and control group. Majority of subjects in both caregivers and controls believe that stroke can occur more than one time and affects daily activity but it was not found to be significant. Similar result was found in study done by Aldebasi KA which reported that Ischemic Stroke is preventable disease (41\%). $58.8 \%$ of the participants had insufficient attitude towards the prevention of stroke attack. ${ }^{8}$ 


\section{Conclusion}

As the knowledge, perception percentage and positive attitude for patients among care givers \& controls was limited so there is urgent need of community-based awareness program. The level of KAP toward stroke risk factors and warning symptoms was adequate among the majority of participants. Although good KAP was associated with high education and young age.

\section{Limitations of the Study}

Our study cannot provide information about occurrence of stroke in the source population as they are restricted to admitted patients of concerned hospital. Chances of selection bias can't be ruled out as the controls are also selected from same hospital setup and not from the community.The results of present study could not be extrapolated to general population as it's a hospital-based study.

Authors Contribution: All authors have contributed equally.

\section{Conflict of Interest: Nil.}

\section{References}

1. Dalal P, Bhattacharjee M, Vairale J, Bhat P. UN millennium development goals: can we halt the stroke epidemic in India? Ann Indian. Acad Neurol. 2007;10:130-136.

2. Srivastava AK, Prasad K. A study of factors delaying hospital arrival of patients with acute stroke. Neurol India 2001;49:2726
3. Das S, Banerjee T. Stroke: Indian Scenario. Circ. 2008;118:2719-2724

4. Aldebasi KA, Alamri NM, Alqahtani AM, Alsadah A, Alzahrani GS, Almutairi AM et al. Knowledge, Attitude and Practice towards Stroke Risk Factors and Warning Symptoms in Saudi Arabia, 2017. Egypt J Hosp Med. 2017;69(3).

5. Sorganvi V, Kulkarni MS, Kadeli D, Atharga S. Risk factors for stroke: A case control study. Int J Cur Res Rev. 2014;06(3):4652.

6. World Health Organization (WHO) STEPS Stroke Manual. STEPwise Approach to Stroke Surveillance Manual. http://www.who.int/ chp/steps/Stroke/en.pdf, last accessed on Sept 12, 2016

7. Pandian JD, Kalra G, Jaison A, Deepak SS, Shamsher S, Singh Y, et al. Knowledge of stroke among stroke patients and their relatives in Northwest India. Neurol India 2006;54:152-156.

8. Aldebasi KA, Alamri NM, Alqahtani AM, Alsadah A, Alzahrani GS, Almutairi AM et al. Knowledge, Attitude and Practice towards Stroke Risk Factors and Warning Symptoms in Saudi Arabia, 2017. Egypt J Hospl Med. 2017 Oct 1;69(3).

9. Bhat AB, Ahmed KI, Sharna RN, Barman S. Knowledge, Attitude and Practice Regarding Stroke amongst the Close Relatives of Stroke Victims at a Tertiary Care Hospital in Bangladesh. Int J Cardiovasc Cerebrovasc Dis. 2016;4(3):3540.

How to cite this article: Singh S. K, Dhar D.K. Knowledge, attitude and practice about the risk factors of ischemic stroke and warning symptoms- A case control study. J Community Health Manag. 2018;5(4):205-208. 